\title{
Expression of Steroidogenic Enzyme Genes in the Equine Feto-Placental Unit
}

\author{
Telhisa HASEGAWA*, Fumio SATO, Yasuo NAMBO and Nobushige ISHIDA \\ Laboratory of Molecular and Cellular Biology, Equine Research Institute, 321-4 Tokami-Cho, Utsunomiya \\ 320-0856, Japan. FAX: 81-28-647-0686 E-Mail: telhisah@center.equinst.go.jp
}

The expression of equine cytochrome P450 aromatase gene (CYP19) in various tissues include placenta and fetal gonads were examined by reverse-transcription polymerase chain reaction (RT-PCR), in addition to northern blot analysis of cytochrome P450 steroid $17 \alpha$ hydroxylase/C17-20 lyase gene (CYP17) and 3 $\beta$-hydroxysteroid dehydrogenase $\Delta 5-\Delta 4$ isomerase gene (HSD3B). Prior to this, testicular expression of CYP19 mRNA in adolescence was confirmed by RT-PCR and successive sequencing. The successful amplification of RT$P C R$ and nucleotide sequence of the PCR products meant the equine testis expresses CYP19 $m R N A$. In the RT-PCR of the pregnancy samples, CYP19 was expressed only in the placenta and not in the fetal gonads. The equine fetal gonads, which express CYP17, should convert progestins into androgens to supply substrates for aromatization in placenta expressing CYP19. It is suggested that the fetal gonads are the major androgen source in equine gestations, and this function will not be affected by the fetal gender.

Key words: CYP19, CYP17, HSD3B, feto-placental unit
J. Equine Sci.

Vol. 12, No. 1

pp. 25-32, 2001
The research to elucidate the mechanisms of unique hormonal patterns in the equine gestational period is one of the interests in the reproductive biology. A secretion of equine chorionic gonadotropin (eCG) and successive luteinization of accessory corpora lutea and progesterone $\left(\mathrm{P}_{4}\right)$ secretion are well-known characteristics in the equine early pregnancy $[4,15]$. Furthermore, in the mid-gestational period and thereafter, the fetal gonads become strikingly hypertrophic [12], and in the same time, the maternal blood estrogen levels elevate strikingly [20]. Generally in the mid-gestational period of mammalian species, maternal blood $\mathrm{P}_{4}$ levels are maintained by the corpora lutea or the placenta. However, in the maternal peripheral $\mathrm{P}_{4}$ levels are maintained lower for a long time from mid- to late-gestation in horses [19], and $\mathrm{P}_{4}$ level is lower than the other detectable progestins even in the umbilical venous blood, that flow from placenta to fetus. Several hypotheses presented to explain this phenomenon do not support the insignificance of

This article was accepted March 20, 2001.

*correspondence author. e-mail: telhisah@center.equinst.go.jp progestins in the maintenance of equine gestation. Nevertheless, synthesis of hydroxylated pregnanes, so called "5 $\alpha$-pregnanes", and emerging increase of their blood levels imply that progestins are actually catabolized in equine placenta [9]. It is estimable to elucidate the relationship and participation of the fetal gonads and placenta in the steroidogenesis during equine gestation period.

Although, relatively high levels of blood estrogens are detected in the gestation period of several mammalian species include humans, their synthetic pathways are not common as well as the significance of their secretion. In addition to estrone $\left(\mathrm{E}_{1}\right)$ and estradiol-17 $\beta\left(\mathrm{E}_{2}\right)$, equine specific $\mathrm{B}-\mathrm{nucleus}$ unsaturated estrogens, equilin and equilenin, their hydroxylates and sulfates are detected from circulating blood and urine samples of pregnant mares [15]. Raeside et al. (1979) inferred that the precursors for estrogen synthesis are supplied by fetus because of high levels of dehydroepiandrosterone (DHEA) and pregnenolone $\left(\mathrm{P}_{5}\right)$ in the umbilical arterial blood [26]. In this point, synthesis of $\mathrm{E}_{1}$ and $\mathrm{E}_{2}$ in the mares during mid- and late- gestation periods might be considered as 
the same cooperative basis of fetus and placenta as in the primates [3]. As the possible precursors for equilin and equilenin are exist in the fetal tissues, the participation of fetal gonads to synthesize these equine specific estrogens is also implicated [27].

The final step of estrogen biosynthesis is an aromatization of A-nucleus of the C19 androgens. In the first decades of research in biosynthesis of estrogens, human placenta and equine testis were used [21]. Pigon et al. (1961) reported that the amount of estrogens and estrogen derivatives in the urine of mature stallion is higher than the pregnant mares but they decrease after castration [23]. Baggett et al. (1959) demonstrated that equine testis can convert testosterone into estrogens [7], and $\mathrm{Oh}$ and Tamaoki (1973) corroborated the microsomal localization of aromatization activity in equine testis [22]. Of course, small amount of testicular aromatizations could be observed in many mammalian species, but the extremely high level syntheses of estrogens in equine and porcine testes must be exceptional [32]. Biosyntheses of steroid hormones are regulated by the expression and the function of specific steroidogenic enzymes. $3 \beta$-hydroxysteroid dehydrogenase $\Delta 5-\Delta 4$ isomerase ( $3 \beta$-HSD) converts $3 \beta$-hydroxy- $\Delta 5$-enesteroids into 3 -keto- $\Delta 4$-ene-steroids reversibly, cytochrome P450 steroid 17 $\alpha$-hydroxylase/C17-20 lyase (CYP17) catalyzes $17 \alpha$-hydroxylation and $\mathrm{C}_{20-21}$ side chain cleavage, and at last cytochrome $\mathrm{P} 450$ aromatase (CYP19) aromatizes androgens into estrogens.

The authors previously reported the northern blot analysis of equine tissues include fetal gonads and placenta with radio labeled cDNA probes of $3 \beta$-HSD gene $(H S D 3 B)$, and demonstrated that fetal gonads of both genders do not express $H S D 3 B$ in contrast to placenta, that expresses $H S D 3 B$ in high levels [16]. In this study, we intended to elucidate two points, the expression of CYP19 in the adult equine testis, fetal gonads and placenta by RT-PCR, and the source and the mechanism of estrogens in equine gestation by multiple tissue northern blot with probes for equine $H S D 3 B$ and $C Y P 17$ in combination with RT-PCR of CYP19 mRNA.

\section{Materials and Methods}

\section{RNA preparations}

Tissue samples of adrenal gland, testis, kidney, liver, and gluteus muscle were collected from 2-years-old
Thoroughbred colt, ovaries from 3 days old Thoroughbred foal were collected after necropsy. Corpus luteum (125 days of pregnancy), placentas (125, 180 and 270 days of pregnancy), fetal testis (155 days of pregnancy), and fetal ovary (125 days of pregnancy) were collected by Caesarean sections from pregnant Thoroughbred mares of various ages (from 6 to 15 year old) under sevoflurane-oxygen inhalation anesthesia $[1,16]$. The samples were stored in $-80^{\circ} \mathrm{C}$ until extraction of total RNAs. Total RNA was extracted by guanidinium isothiocyanate/ $\mathrm{CsCl}$ ultracentrifugation [28].

Reverse Transcription Polymerase Chain Reaction (RT-PCR)

First strand cDNAs for RNA samples were synthesized by modified Moroney murine leucopenia virus reverse transcriptase (modified MMLV-RT: SuperScript II preamplification system; GIBCO BRL, Bethesda, U.S.A.). Polymerase chain reactions (PCR) from the first strand cDNAs were performed with GeneAmp PCR System 9600 and GeneAmp PCR Reagent (Perkin Elmer, Urayasu, Japan).

Primers specific to the equine CYP19 were designed from the nucleotide sequences for equine CYP19 [2, 11]:

arom-F

5'-GGAATTCGAGAAAGGCATCATATTTAACA-3' arom-R

5'-GGAATTCCAAGAAATCTTAAAGAAGATG-3' arom-Fl1

5'-GAATTCGCGTGAGATCAAGGAGCACAAGATG-3' arom-F2

5'-GAGAAAGGCATCATATTTAACAATAA-3' arom-R2

5'-GGAATTCCAAGAAATCTTAAAGAAGATGTTTG-3'

The thermal cycle was $95^{\circ} \mathrm{C}$ for $4 \mathrm{~min}$ of predenature, and 30 cycles of $95^{\circ} \mathrm{C}$ for 1 min denature $55^{\circ} \mathrm{C}$ for $2 \mathrm{~min}$ annealing and $72^{\circ} \mathrm{C}$ for 3 min extension were followed by $72^{\circ} \mathrm{C}$ for 7 min extension in $100 \mu \mathrm{l}$ of reaction mixture.

\section{Cloning of the PCR fragment}

Molecular size of PCR-amplified fragments were determined by agarose gel electrophoresis ( $1 \%$ agarose in $1 \times \mathrm{TAE}$ ), and purified with GENE CLEAN II kit (BIO 101, La Jolla, U.S.A.). Purified PCR fragments were ligated into plasmid vector pGEM-T Easy (Promega, Madison, U.S.A.). Escherichia coli XL-1 Blue MRF' cells (Stratagene, San Diego, U.S.A.) were 
transformed with the ligated DNA. The transformants were selected by blue-white colony selection with IPTG and X-gal on the LB agar plates containing $50 \mu \mathrm{g} / \mathrm{m} l$ ampicillin.

\section{Nucleotide sequencing and computer analysis}

Nucleotide sequence of the plasmid inserts were determined by Sanger's dideoxynucleotide chain termination method [29] with the A.L.F. automated sequencer (Pharmacia-Biotech, Tokyo, Japan), fluorescein labeled sequence primers (M4 and RV-M; Takara Shuzo, Kyoto, Japan), and SequiTherm LongRead Cycle Sequencing Kit (Epicentre Technologies, Madison, U.S.A.). Obtained sequences were analyzed with the DNA analyzing software package DNASIS-Mac (Hitachi Software Engineering, Yokohama, Japan).

\section{cDNA probes}

Inserts were excised from the plasmid clones for equine CYP17 cDNA [17] by restriction endonuclease $K p n \mathrm{I}$ and $H S D 3 B$ cDNA [16] by restriction endonuclease BamHI. Excised inserts were purified with GeneClean II kit (BIO 101, La Jolla, U.S.A.), and labeled with $\left[\alpha_{-}{ }^{32} \mathrm{P}\right]$ dCTP (Rediprime DNA Labeling System; Amersham, Tokyo, Japan).

\section{Northern blot analysis}

Multiple tissue blots were performed with RNA samples described above. Twenty micrograms of total RNA from each tissue was separated by electrophoresis in $1.0 \%$ agarose 3 -[ $\mathrm{N}$-morpholino]-propanesulfonic acid (MOPS)-formamide-formaldehyde gel [28]. Separated nucleic acids were transferred to a piece of positively charged nylon membrane (HyBond $\mathrm{N}^{+}$; Amersham, Tokyo, Japan), and hybridized with the radio labeled probe for $H S D 3 B$. After the detection of $H S D 3 B$, probe for $H S D 3 B$ was stripped by boiling in $50 \%$ formamide $6 \times \mathrm{SSPE}$ for $30 \mathrm{~min}$ at $65^{\circ} \mathrm{C}$ and reprobed with the radio labeled probe for $C Y P 17$. BAS imaging plate scanner (BAS2500 system; Fuji Photo Film, Tokyo, Japan) was used to visualize the localization of radioactivities.

\section{Results}

The results of agarose gel electrophoresis of the RTPCR products were shown in Fig. 1. PCR products around $350 \mathrm{bp}$ from a pair of primers arom-F2/arom-R and around $750 \mathrm{bp}$ from another pair of primers arom-
F11/arom-R2 were detected in samples from testis of an adult (adolescent) colt, and placentas (days 125, 180 and 270 of pregnancy). There were no signs of amplification in the samples from adrenal gland, corpus luteum (day 125 of pregnancy), fetal ovary (day 125 of pregnancy), fetal testis (day 155 of pregnancy), and 3-days-old foal ovary, as well as adult nonsteroidogenic liver, kidney and muscle. Sequence analysis was performed on the cloned PCR products from testicular cDNA. The exact length of the shorter PCR fragment around $350 \mathrm{bp}$ was $351 \mathrm{bp}$, and that for the longer one was $763 \mathrm{bp}$. The nucleotide sequences for both two kinds of PCR fragments were identical to the previously reported CYP19 sequences (Fig. 2) [2, $8]$. The shorter product was completely included in the longer one, and the nucleotide sequences of the redundant part were identical with each other, as well as with the reported sequence.

By northern blot analysis, the equine CYP17 mRNAs were expressed in adult testis, adrenal gland and fetal gonads (Fig. 3), in contrast to the equine $H S D 3 B$ mRNAs, that expressed in adult testis, adrenal gland, corpus luteum, and placenta, but not detected in fetal gonads of both genders [22]. Non-steroidogenic tissues, liver, kidney and muscle did not express both two steroidogenic enzymes, while the 3-days-old foal ovary expressed both. The expression levels of CYP17 in the fetal gonads were higher than the testis and the adrenal gland.

\section{Discussion}

Metabolic pathways of steroid synthesis are so common in various species that the similarity of function or structure of steroidogenic enzyme in each step is conserved over species. In steroidogenic tissues, species of steroid hormone as the final products are determined by kinds of substrates, natures and expression levels of steroidogenic enzymes. The authors previously reported on the cDNA cloning of CYP17 [17] and HSD 3B [16]. It is obvious that estrogens are synthesized in the equine testis by old literature [7], and CYP19seemed to be expressed in the equine testis. Actually, early studies of conversion from androgens to estrogens had been conducted using equine testis [21] but it is more recent that equine CYP19 has been demonstrated as a single protein molecule in an equine testis [5, 10, 14, 30].

As result of RT-PCR experiment, a $351 \mathrm{bp}$ (primers 

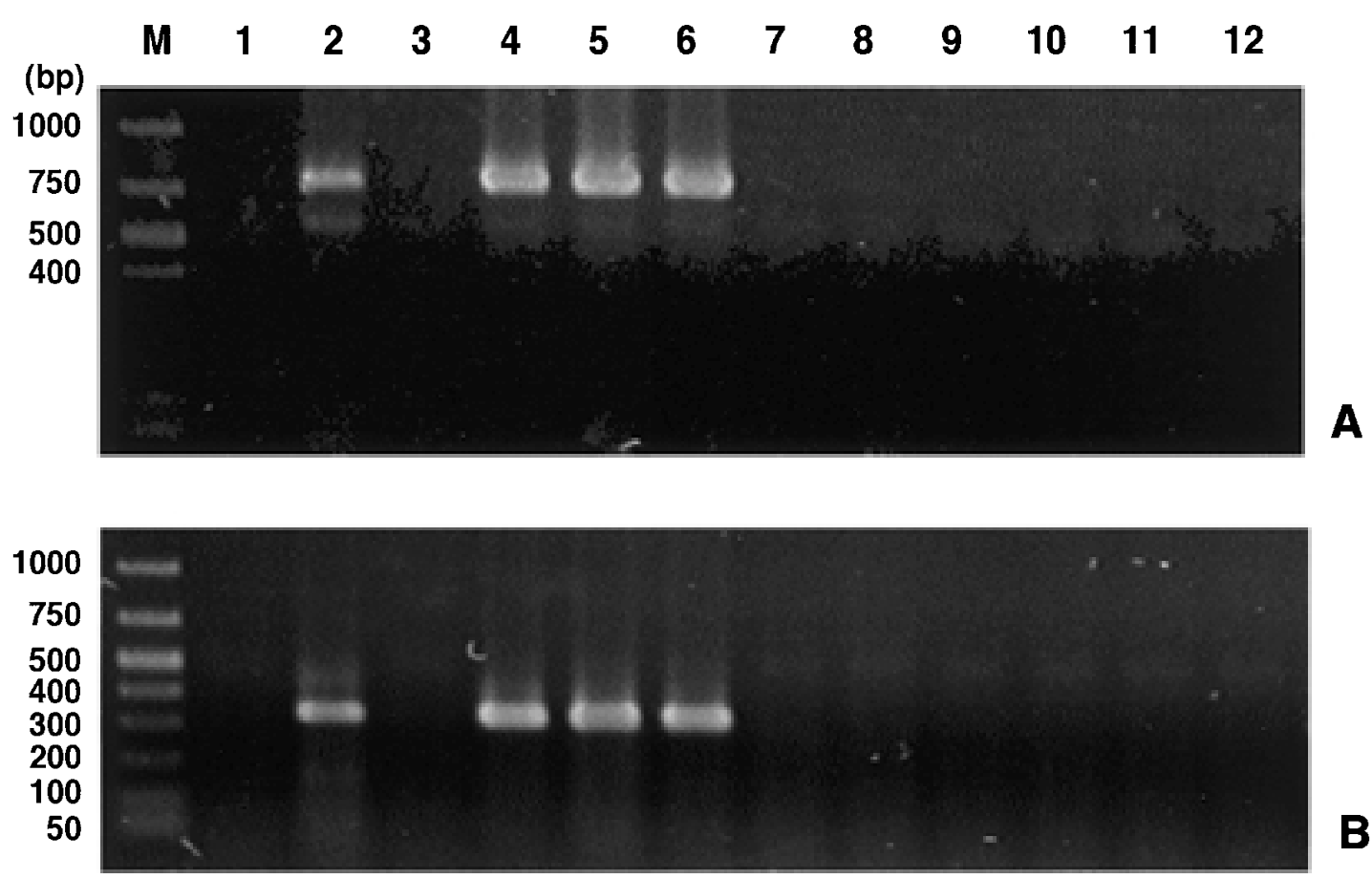

Fig. 1. Agarose gel electrophoresis of RT-PCR products. A: RT-PCR products for primers arom-F11/R2, B: RT-PCR products for primers arom-F2/R, M: molecular size marker (50-1000 bp), 1: adrenal gland*, 2: testis*, 3: corpus luteum (125 dpc), 4: placenta (125 dpc), 5: placenta (180 dpc), 6: placenta (270 dpc), 7: fetal ovary (125 dpc), 8: fetal testis $(155 \mathrm{dpc})$, 9: ovary (3 dpd), 10: liver*, 11: kidney*, 12: muscle*, dpc: days post coitus, dpd: days post delivery, *: 2 to 3 years old adults.

arom-F2/arom-R2) and a 763 bp (primers arom-F11/ arom-R) PCR products were amplified from equine testicular RNA sample (Fig. 1). We confirmed that the nucleotide sequences of the PCR products were identical to the previously reported equine CYP19 cDNA expressed in a primary corpus luteum at early pregnancy [2] and human chorionic gonadotroropin (hCG) treated ovarian follicles [8]. The nucleotide sequence of the shorter $351 \mathrm{bp}$ PCR product was completely included in those of the longer $763 \mathrm{bp}$ product.

Other than the adult testis, two kinds of PCR products were only detected in 3 samples of placentas (Fig. 1). It is in concomitant with previous report on the placental localization of CYP19 protein [18]. The failure to amplification by both two sets of primers from other tissues implies that CYP19 mRNA was not or rarely expressed in these tissues. The corpus luteum is known to express CYP19 in the early pregnancy. Albrecht et al. (1997) demonstrated that the corpora lutea of cycling mares, days from 29 to 35 and from 42 to 45 of pregnancy express CYP19 mRNA. They discussed that the luteal expression of $H S D 3 B, C Y P 17$ and CYP19 is constant before the onset of eCG secretion, but promotional effect of eCG on the CYP17 expression results in the increase of estrogen production [2]. In this study, the corpus luteum at mid-gestation showed no evidence for expression of CYP17 and CYP19, so the luteal contribution to the synthesis of androgens and estrogens seemed to be very limited in this period. Furthermore, as the luteal expression of $H S D 3 B$ in this period is lower than that of placenta in same period, it is suggested that corpus luteum handed over the responsibility supplying C21 steroid substrates necessary to maintain pregnancy.

In the ovarian follicles, granulosa cells and thecal cells cooperate with each other to synthesize estrogens, and in this system, so called "Armstrong-Dorrington's two-cell model" [6], granulosa cells express $H S D 3 B$ and CYP19 while thecal cells express CYP17. These concepts were also accepted to be applicable in the feto-placental unit [3]. In the human feto-placental unit, the estrogen synthesis in late-gestation is supported by the cooperative function of the placenta 


\begin{tabular}{|c|c|c|c|c|c|c|c|}
\hline & & 10 & 20 & 30 & 40 & 50 & \\
\hline$A F 031520$ & 1 & TTCCTAACAG & CCGTGCATCA & TTAGCAAAAC & TCATCATCTT & CAAGAGTCCG & 50 \\
\hline AEO 31520 & 51 & GAAACTAGAA & GTGACCAGCA & GACTCAGGCC & TTTACATTGC & TTCGCCTGAG & 100 \\
\hline $\operatorname{aromF11/R2}$ & 1 & & & & $\mathrm{~m}$ & Trooctras & 13 \\
\hline AF0 31520 & 101 & ATCAAGGAAC & ACAAGATGAT & TTTGGAAATG & CTAAACCCGA & TGCATTATAA & 150 \\
\hline $\operatorname{aromF} 11: \mathrm{R} 2$ & 14 & HAMAOAGC & ACAAGMAAT & TTTGGAAATG & CTAAACCCGA & TGCATTATAA & 63 \\
\hline $\mathrm{AF} 031520$ & 151 & CCTCACCAGC & ATGGTGCCCG & AAGTCATGCC & TGTCGCCACC & TTGCCCATTC & 200 \\
\hline $\operatorname{aromFl1} \mathrm{R} 2$ & 64 & CCTCACCAGC & ATGGTGCCCG & AAGTCATGCC & TGTCGCCACC & TTGCCCATTC & 113 \\
\hline$A F 031520$ & 201 & TGCTGCTCAC & TGGCTTTCTT & TTCTTTGTTT & GGAATCATGA & AGAAACATCC & 250 \\
\hline $\operatorname{aromF11/R2}$ & 114 & TGCTGCTCAC & TGGCTTTCTT & TRCTTTGTTT & GGAATCATGA & AGAAACATCC & 163 \\
\hline $\mathrm{AF} 031520$ & 251 & TCAATACCAG & GCCCTGGCTA & TTGCATGGGA & ATCGGGCCCC & TCATTTCCCA & 300 \\
\hline $\operatorname{aromF} 11 / R 2$ & 164 & TCAATACCAG & GCCCTGGCTA & TTGCATGGGA & ATCGGGCCCC & TCATTTCCCA & 213 \\
\hline$A F 031520$ & 301 & CCTCCGGTTC & CTGTGGATGG & GGCTTGGCAG & TGCCTGCAAC & TACTACAACA & 350 \\
\hline $\operatorname{aromF} 11 \cdot \mathrm{R} 2$ & 214 & CCTCCGGTTC & CTGTGGATGG & GGCTTGGCAG & TGCCTGCAAC & TACTACAACA & 263 \\
\hline AF0 31520 & 351 & AGATGTATGG & AGAATTCGTA & AGAGTCTGGA & TCAGTGGAGA & GGAAACGCTC & 400 \\
\hline $\operatorname{aromF1} 1 / \mathrm{R} 2$ & 264 & AGATGTATGG & AGAATTCGTG & AGAGTCTGGA & TCAGTGGAGA & GGAAACGCTC & 313 \\
\hline AF0 31520 & 401 & GTTATTAGCA & AGTCCTCAAG & TACCTTCCAC & ATCATGAAAC & ACGATCACTA & 450 \\
\hline $\operatorname{aromF} 11 / R 2$ & 314 & GTTATTAGCA & AGTCCTCAAG & TACCTTCCAC & ATCATGAAAC & ACGATCACTA & 363 \\
\hline $\mathrm{AF} 031520$ & 451 & CTCCTCCCGA & TTTGGCAGCA & CATTTGGGTT & GCAGTATATG & GGCATGCATG & 500 \\
\hline $\operatorname{aromF11/R2~}$ & 364 & CTCCTCCCGA & TTTGGCAGCA & CATTIGGGTT & GCAGTATATG & GGCATGCATG & 413 \\
\hline $\operatorname{aromF} 2 / \mathrm{R}$ & 1 & & & & & 8 & 1 \\
\hline AE0 031520 & 501 & AGAATGGCGT & САTATTTAAC & AATAACCCAG & CCGTCTGGAA & AGCTTTGCGG & 550 \\
\hline $\operatorname{aromF} 11 / \mathrm{R} 2$ & 414 & AGAATGGCGT & CATATTTAAC & AATAACCCAG & CCGTCTGGAA & AGCT'TGCGG & 463 \\
\hline $\operatorname{aromF} 2 / \mathrm{R}$ & 2 & AGAMEGOGI & GMAMTHAS & XPMAXCCCAG & CCGTCTGGAA & AGCTTTGCGG & 51 \\
\hline $\mathrm{AF} 031520$ & 551 & CCTTTCTTTG & TAAAAGCTTT & GTCTGGCCCC & AGCCTTGCGC & GCATGGTGAC & 600 \\
\hline $\operatorname{aromF11/R2}$ & 464 & CСTTTCTTTG & TAAAAGCTT' & GTCTGGCCCC & AGCCTTGCGC & GCATGGTGAC & 513 \\
\hline $\operatorname{aromF} 2 / R$ & 52 & ССTTTCTTTG & TAAAAGCTTT & GTCTGGCCCC & AGCCTTGCGC & GCATGGTGAC & 101 \\
\hline $\mathrm{AFO} 31520$ & 601 & AGTT'TGTGT'T & GAATCCGTCA & ACAACCATCT & GGACAGGTIG & GACGAGGTCA & 650 \\
\hline $\operatorname{aromF} 11 / R 2$ & 514 & AGT'TGTGTT & GAATCCGTCA & ACAACCATCT & GGACAGGTTG & GACGAGGTCA & 563 \\
\hline $\operatorname{aromF2} / \mathrm{R}$ & 102 & AGTTTGTGTT & GAATCCGTCA & ACAACCATCT & - GGACAGGTTG & GACGAGGTCA & 151 \\
\hline$A F 031520$ & 651 & CCAATGCGT" & GGGCCATGTC & AACGTGTTGA & CCCTCATGCG & ACGTACCATG & 700 \\
\hline $\operatorname{aromF} 11$ / R2 & 564 & CCAATGCGTT & GGGCCATGTC & AACGTGTTGA & CCCTCATGCG & ACGTACCATG & 613 \\
\hline $\operatorname{aromF} 2 / \mathrm{R}$ & 152 & CCAATGCGTT & GGGCCATGTC & AACGTGTTGA & CCCTCATGCG & ACGTACCATG & 201 \\
\hline AF031520 & 701 & CTGGACGCTT & CCAACACCCT & CTTCCTGAGG & ATCCCCTTGG & ACGAGAAAAA & 750 \\
\hline $\operatorname{aromF} 11 / \mathrm{R} 2$ & 614 & CTGGACGCTT & CCAACACCCT & CTICCTGAGG & ATCCCCTTGG & ACGAGAAAAA & 663 \\
\hline $\operatorname{aromf} 2 / R$ & 202 & CTGGACGCTT & CCAACACCCT & CMTCCTGAGG & ATCCCCTTGG & ACGAGAAAAA & 251 \\
\hline AF0 31520 & 751 & CATCGTGCTT & AAAATCCAGG & GTTATTVTTA & TGCATGGCAG & GCTCTCCTPA & 800 \\
\hline $\operatorname{aromF11/R2~}$ & 664 & CATCGTGCTT & AAAATCCAGG & GTTATTTTGA & TGCATGGCAG & GCTCTCCTTA & 713 \\
\hline $\operatorname{aromF} 2 / R$ & 252 & CATCGTGCTT & AAAATCCAGG & GTTATTTTGA & - TGCATGGCAG & GCTCTCCTTA & 301 \\
\hline $\mathrm{AF} 031520$ & 801 & TCAAACCAAA & САTCTTCTT' & AAGATTTCTT & GGCTATCCAG & AAAGCATCAA & 850 \\
\hline $\operatorname{aromF11/R2}$ & 714 & TCAAACONA & CXTETTMTI & AActmm MW & GANAmCC. & & 763 \\
\hline $\operatorname{arcmF2/R}$ & 302 & TCAAACCAAA & 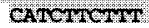 & ARCAmmorT & GaAmiree. . & $\ldots \ldots \ldots$ & 351 \\
\hline
\end{tabular}

Fig. 2. Nucleotide sequence of RT-PCR products for equine CYP19. PCR primers were indicated with box shadows. AF031520: complete cDNA sequence for equine CYP19 [8], arom-Fl1/R2 and arom-F2/R: see text.

expressing $3 \beta$-HSD and CYP19, and the fetal adrenal gland expressing CYP17. As the adrenal gland of term human fetus has also $3 \beta$-HSD activities, the fetal adrenal gland may possible to produce androgens from
$\mathrm{P}_{5}$ or cholesterol [13]. In the adrenal cortex, distinct populations of steroidogenic enzymes are expressed. The each zone of the adrenal cortex secretes distinct products, aldosterone from zona glomerulosa, cortisol 


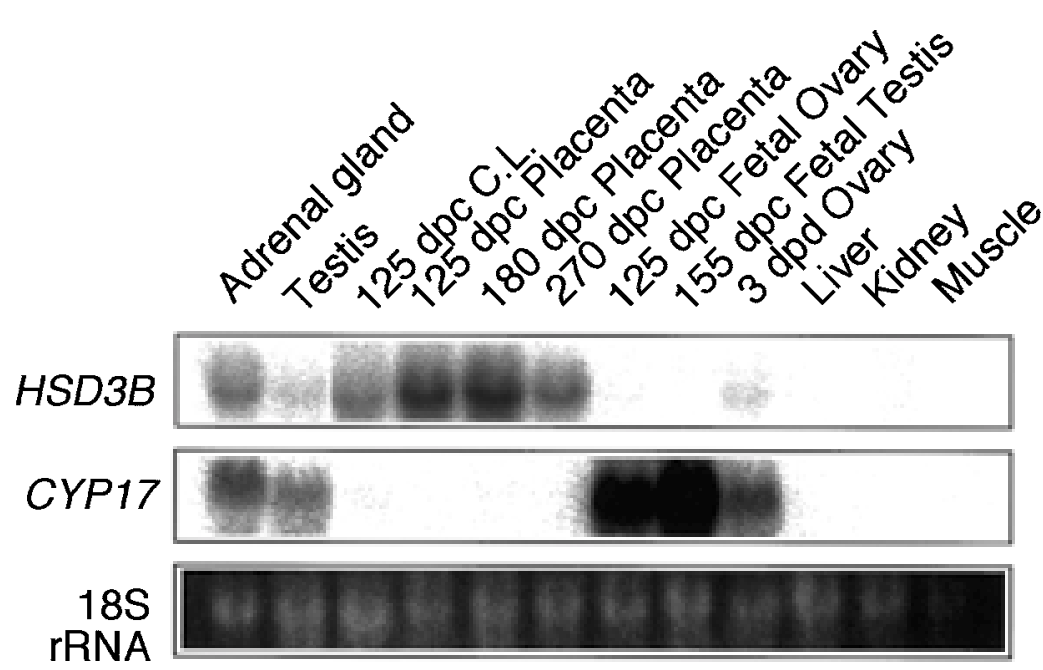

Fig. 3. Multiple tissue northern blot analysis for HSD $3 B$ and CYP17. $20 \mu \mathrm{g}$ of total RNA in each lane was analyzed. Adult adrenal grand, testis, and nonsteroidogenic control, liver, kidney and muscle, were also analyzed. dpc: days post coitus, dpd: days post delivery.

or corticosterone from zona fasciculate, and zona reticularis sulfonates unnecessary DHEA by sulfokinase. DHEA sulfonate (DHEA-S) produced by human fetal adrenocortex may be catalyzed to DHEA by placental sulfatase and aromatized in placenta. Thus, in primates, fetal adrenal gland is an additional major source of DHEA as a substrate to produce estrogens as well as maternal adrenal gland.

In horses, B-unsaturated equine estrogens, equilin and equilenin, $\mathrm{E}_{1}$, estradiol-17 $\beta$ and $-17 \alpha$ exist in the maternal blood and urine at high levels. Although placenta seemed responsible to produce estrogens, as estrogens could be synthesized by incubating placental tissue with various precursors. Raeside et al. (1973) inferred that equine fetal gonads are responsible to the placental estrogen synthesis as well as human fetal adrenal because of drastic decrease of estrogen levels in maternal urine after removal of fetal gonads [25]. Here we compared the expression of genes for major steroidogenic enzymes, HSD 3B, CYP17 and CYP19 in the fetal gonads and placenta, and the prominent expression of CYP17 in the fetal gonads was observed while the placenta showed no expression. In contrast to $C Y P 17, H S D 3 B$ and $C Y P 19$ was expressed in the placenta, while the fetal gonads showed no expression.

The observations suggested that the estrogen synthesis in the equine pregnancy is supported by a cooperative function to supply substrates between fetus and placenta. Since there are high levels of $\mathrm{P}_{5}$ and
DHEA in equine fetal gonads and gonadal venous blood [24], equine fetal gonads may produce DHEA from $\mathrm{P}_{5}$ as a substrate by $C Y P 17$. $\Delta 4$-steroids may not be produced by fetal gonads because of lack of $H S D 3 B$ expression, and DHEA may be a final product in fetal gonads. Therefore, it is suggested that $\Delta 4$-androgens necessary for estrogen synthesis by placental CYP19 are converted from DHEA, supplied by fetus, by placental $3 \beta$-HSD. While blood testosterone levels in pregnant mares vary like estrogens [31], this testosterone should be synthesized by placenta because of lack of $H S D 3 B$ expression in fetal gonads. In this study, fetal adrenal gland had not been tested. It may be important to discuss the contribution of fetal adrenal gland to the feto-placental steroid synthesis by DHEA-S pathway, but linear growth of the equine fetal adrenal gland in midgestation to parturition [33] is different from the patterns in the equine fetal gonads, that grow quickly and shrink by late-gestation [4, 12, 15]. The results obviously showed the importance of fetal gonads at least the source of androgen substrate for production of maternal blood estrogens.

Compared with humans, the mechanism of estrogen synthesis in the equine feto-placental unit might be essentially identical only exception that the major contributing organs are gonads, while adrenal gland in humans. However, there may be differences between two species about the significance of increase in maternal estrogen levels. In humans, maternal 
estrogen levels increase continuously, and this may induce various function related to parturition. In ruminants, increase of cortisol in late-gestational period induces placental CYP17, and resultant increase of estrogen level promotes parturition. In horses, it is not acceptable that high levels of estrogens is necessary to induce parturition in human alike, because maternal blood levels of estrogens decrease with the size of fetal gonads, and the decrease of estrogens occurs very early in a basis of parturition timing without rebound just before parturition. Estrogens, which increase in midto late-pregnancy, may act on uterus or uterine blood supply in cooperation with progestins, and inhibit secretion of gonadotropins to maintain pregnancy.

\section{Acknowledgments}

We thank Dr. M. Takahashi (Central Research Laboratories, Ajinomoto Co., Inc., Kawasaki, Japan) and Dr. H. Mukoyama (Department of First Forensic Science, National Research Institute of Police Science, Kashiwa, Japan) for sincere encouragements in achieving this study. We also thank Dr. K. Yamanouchi (Department of Animal Resource Sciences, University of Tokyo, Tokyo, Japan) and Ms. M. Ishida (Shirakawa Institute of Animal Genetics, The Livestock Technology Association, Fukushima, Japan) for technical assistances.

\section{References}

1. Aida, H., Mizuno, Y., Hobo, S., Yoshida, K., and Fujinaga, T. 1996. Cardiovascular and pulmonary effects of sevoflurane anesthesia in horses. Vet. Surg. 25: 164-170.

2. Albrecht, B.A., MacLeod, J.N., and Daels, P.F. 1997. Differential transcription of steroidogenic enzymes in the equine primary corpus luteum during diestrus and early pregnancy. Biol. Reprod. 56: 821-829.

3. Albrecht, E.D. and Pepe, G.J. 1990. Placental steroid hormone biosynthesis in primate pregnancy. Endocr. Rev. 11: 124-150.

4. Allen, W.R. 2001. Fetomaternal interactions and influences during equine pregnancy. Reproduction 121: 513-527.

5. Almadhidi, J., Seralini, G.E., Fresnel, J., Silberzahn, P., and Gaillard, J.L. 1995. Immunohistochemical localization of cytochrome
P450 aromatase in equine gonads. J. Histochem. Cytochem. 43: 571-577.

6. Armstrong, D.T. and Dorrington, J.H. 1977. Estrogen biosynthesis in the ovaries and testes. Adv. Sex Horm. Res. 3: 217-258.

7. Baggett, B., Engel, L.L., Balderas, L., Lanman, G., Savard, K., and Dorfman, R.I. 1959. Conversion of C14-Testosterone to C14-estrogenic steroids by endocrine tissues. Endocrinol. 64: 600-608.

8. Boerboom, D., Kerban, A., and Sirois, J. 1999. Dual regulation of promoter II- and promoter $1 \mathrm{f}$ derived cytochrome $\mathrm{P} 450$ aromatase transcripts in equine granulosa cells during human chorionic gonadotropin-induced ovulation: a novel model for the study of aromatase promoter switching. Endocrinol. 140: 4133-4141.

9. Chavatte, P., Holtan, D., Ousey, J.C., and Rossdale, P.D. 1997. Biosynthesis and possible biological roles of progestagens during equine pregnancy and in the newborn foal. Equine Vet. J., Suppl. 24: 89-95.

10. Choi, I., Collante, W.R., Simmen, R.C.M., and Simmen, F.A. 1997. A developmental switch in expression from blastocyst to endometrial/ placental-type cytochrome P450 aromatase genes in the pig and horse. Biol. Reprod. 56: 688-696.

11. Choi, I., Simmen, R.C., and Simmen, F.A. 1996. Molecular cloning of cytochrome $\mathrm{P} 450$ aromatase complementary deoxyribonucleic acid from periimplantation porcine and equine blastocysts identifies multiple novel 5'-untranslated exons expressed in embryos, endometrium, and placenta. Endocrinol. 137: 1457-1467.

12. Cole, H.H., Hart, G.H., Lyons, W.R., and Catchpole, H.R. 1933. The development and hormonal content of fetal horse gonads. Anat. Rec. 56: 275-293.

13. Coulter, C.L., Goldsmith, P.C., Mesiano, S., Voytek, C.C., Martin, M.C., Mason, J.I., and Jaffe, R.B. 1996. Functional maturation of the primate fetal adrenal in vivo. II. Ontogeny of corticosteroid synthesis is dependent upon specific zonal expression of $3 \beta$-hydroxysteroid dehydrogenase/ isomerase. Endocrinol. 137: 4953-4959.

14. Eisenhauer, K.M., McCue, P.M., Nayden, D.K., Osawa, Y., and Roser, J.F. 1994. Localization of aromatase in equine Leydig cells. Domest. Anim. Endocrinol. 11: 291-298.

15. Ginther, O.J. 1992. In: Reproductive Biology of the Mare-Basic and Applied Aspects_2nd ed., 1992, Cross Plains: Equiservices.

16. Hasegawa, T., Ishida, M., Harigaya, T., Ishida, N., 
and Mukoyama, H. 1998. Molecular cloning, nucleotide sequence and tissue distribution of equine testicular $3 \beta$-hydroxysteroid dehydrogenase/ $\Delta 5-\Delta 4$ isomerase messenger ribonucleic acid. J. Equine Sci. 9: 45-52.

17. Hasegawa, T., Mukoyama, H., Yoshida, S., and Takahashi, M. 1995. Molecular cloning and nucleotide sequence of equine testicular cytochrome $\mathrm{P} 450$ steroid 17 $\alpha$-hydroxylase/ C17,20-lyase messenger ribonucleic acid. Biol. Reprod. Mono. 1: 615-622.

18. Hinshelwood, M.M., Liu, Z., Conley, A.J., and Simpson, E.R. 1995. Demonstration of tissuespecific promoters in nonprimate species that express aromatase P450 in placentae. Biol. Reprod. 53: 1151-1159.

19. Holtan, D.W., Houghton, E., Silver, M., Fowden, A.L., Ousey, J., and Rossdale, P.D. 1991. Plasma progestagens in the mare fetus and newborn foal. J. Reprod. Fertil., Suppl. 44: 517-528.

20. Nett, T.M., Holtan, D.W., and Estergreen, V.L. 1973. Plasma estrogens in pregnant and postpartum mares. J. Anim. Sci. 37: 962-970.

21. Oh, R. and Tamaoki, B.-i. 1971. Occurrence of 19oxoandrost-4-ene-3,17-dione in the course of oestrogen biosynthesis by equine testicular microsomes. Acta Endocrinol. (Copenh) 67: 665-676.

22. Oh, R. and Tamaoki, B.-i. 1973. Intermicrosomal distribution of aromatizing enzyme system in equine testicular tissue. Acta Endocrinol. (Copenh) 72: 366-375.

23. Pigon, H., Lunaas, T., and Velle, W. 1961. Urinary oestrogens in the stallion. Acta Endocrinol. 36: 131140.

24. Raeside, J.I., Gofton, N., Liptop, R.M., and Milne, F.J. 1982. Isolation and identification of steroids from gonadal vein blood of the fetal horse. J.
Reprod. Fertil., Suppl. 32: 383-387.

25. Raeside, J.I., Liptrap, R.M., and Milne, F.J. 1973. Relationship of fetal gonads to urinary estrogen excretion by the pregnant mare. Am.J. Vet. Res. 34: 843-845.

26. Raeside, J.I., Liptrap, R.M., and Milne, F.J. 1979. A precursor role for DHA in a fetoplacental unit for oestrogen formation in the mare. J. Reprod. Fertil., Suppl. 27: 493-497.

27. Raeside, J.I. and Renaud, R.L. 1985. Identification of $3 \beta$-hydroxy-5,7-androstadien-17-one as a secretory product of the fetal horse gonad in vivo and in vitro. J. Endocrinol. 107: 415-419.

28. Sambrook, J., Fritsch, E.F., and Maniatis, T. 1989. In: Molecular Cloning: A Laboratory Manual 2 ed. 1989, Cold Spring Harbor: Cold Spring Harbor Laboratory Press.

29. Sanger, F., Nicklen, S., and Coulson, A.R. 1989. DNA sequencing with chain terminating inhibitors. Proc. Natl. Acad. Sci. USA. 74: 54635467.

30. Silberzahn, P., Gaillard, J.L., Quincey, D., Dintinger, T., and Al-Timimi, I. 1988. Aromatization of testosterone and 19nortestosterone by a single enzyme from equine testicular microsomes. Differences from human placental aromatase. J. Steroid Biochem. 29: 119125.

31. Silberzahn, P., Zwain, I., and Martin, B. 1984. Concentration increase of unbound testosterone in plasma of the mare throughout pregnancy. Endocrinol. 115: 416-419.

32. Velle, W. 1966. Urinary oestrogens in the male. J. Reprod. Fertil. 12: 65-73.

33. Yamauchi, S. 1979. Histological development of the equine fetal adrenal gland. J. Reprod. Fertil., Suppl. 27: 487-491. 